\title{
Mainstreaming emergency contraception in Ethiopia's public sector: Final project report
}

\author{
Jill Keesbury \\ Population Council \\ Hailegiorgis Aytenfisu \\ Spike Bradford
}

Follow this and additional works at: https://knowledgecommons.popcouncil.org/departments_sbsr-rh

Part of the Demography, Population, and Ecology Commons, Family, Life Course, and Society Commons, International Public Health Commons, Medicine and Health Commons, and the Women's Health Commons How does access to this work benefit you? Let us know!

\section{Recommended Citation}

Keesbury, Jill, Hailegiorgis Aytenfisu, and Spike Bradford. 2007. "Mainstreaming emergency contraception in Ethiopia's public sector: Final project report." Nairobi: Population Council. 


\title{
Mainstreaming Emergency Contraception in Ethiopia's Public Sector
}

\author{
Final Project Report
}

Dr. Jill Keesbury, Population Council, ECafrique

Dr. Hailegiorgis Aytenfisu, Ethiopian Society of Obstetricians and Gynecologists Spike Bradford, Independent Consultant

December 2007

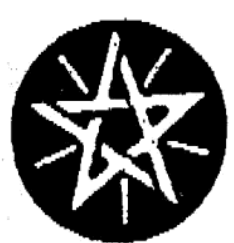

Federal Democratic Republic of Ethiopia

Ministry of Health

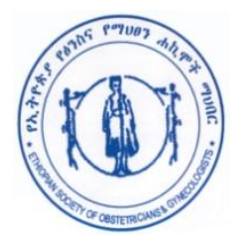




\section{TABLE OF CONTENTS}

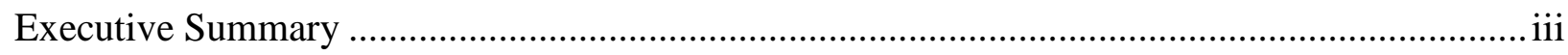

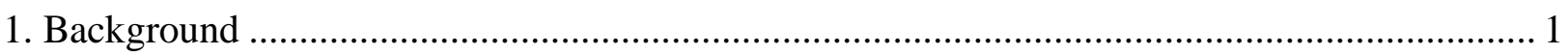

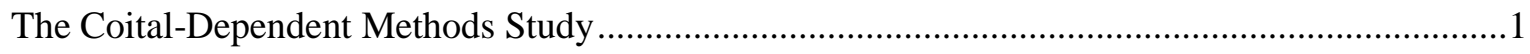

2. Mainstreaming EC in Ethiopia's Public Sector................................................................. 2

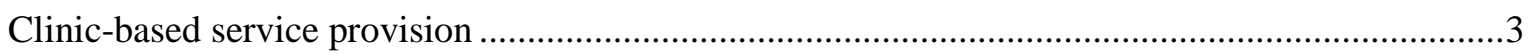

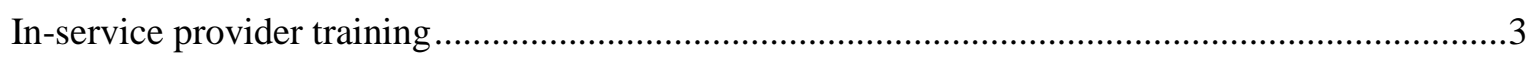

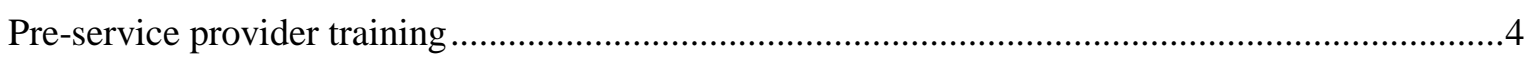

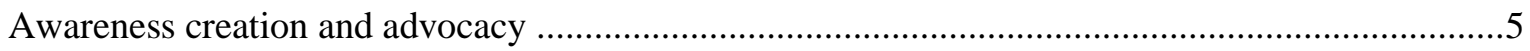

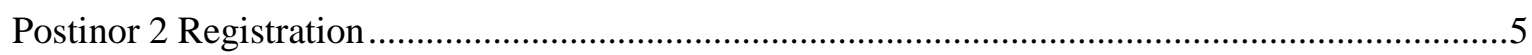

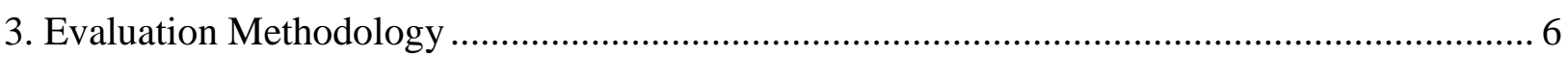

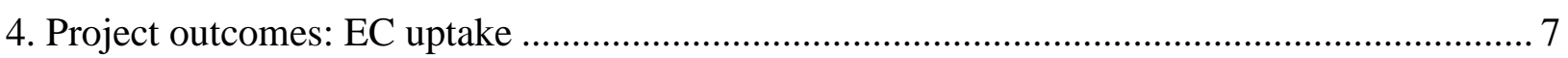

EC can be effectively integrated into Ethiopia's public sector method mix. ...................................

Project performance varied widely across the regions...............................................................

FGAE clinics involved in the CDM study were among the highest performing facilities..................8

5. Project Outcomes: Client Characteristics and Context of EC Use........................................ 9

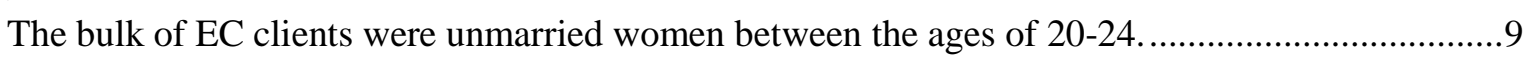

Men were actively involved in their partner's decision to use EC...............................................

EC is most frequently used after unprotected sex, rarely after sexual assault ................................11

Repeat use of EC is low, and providers are successful at "bridging" clients to other

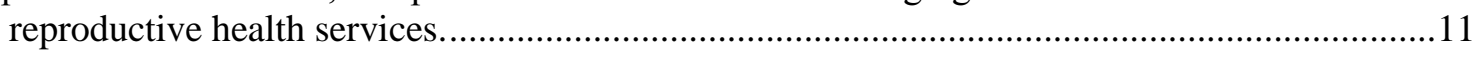

6. Project outcomes: Provider capacity …......................................................................... 12

Trained providers were more likely to dispense and provide information on EC............................12

Training had limited impact on providers' generally high knowledge of specific aspects of

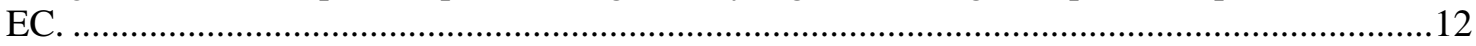

Providers were more conservative than clients in their perceptions of appropriate EC users..........13

EC training and provision in Ethiopia is biased toward Postinor 2..............................................14

7. Project Outcomes: Public Awareness and Access ............................................................. 14

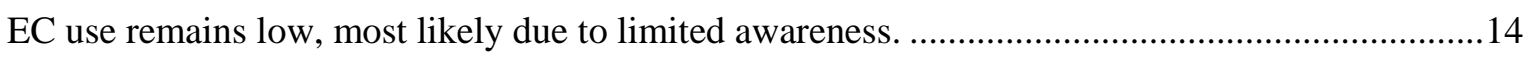

Clients who were aware of EC demonstrated high levels of knowledge. ......................................14

Television adverts and clinic-level outreach were the most successful outreach activities.............15

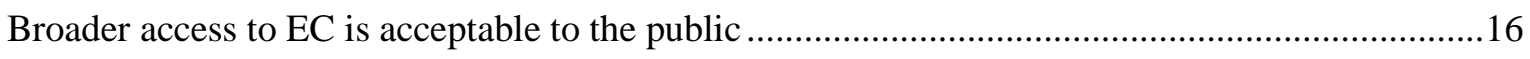

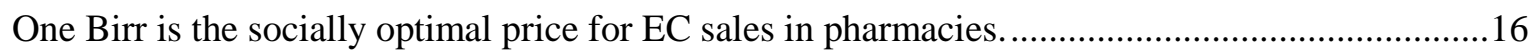

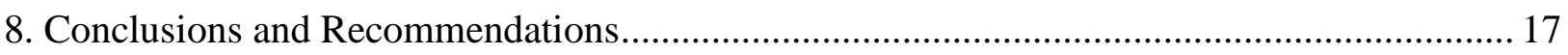

Introduce EC as an essential element of the country's family planning method mix. .....................17

Ensure that $\mathrm{EC}$ is also provided as part of post-rape care by expanding points of access................17

Equip Community-based Reproductive Health Agents (CBRHAs) to deliver EC. ..........................18

Incorporate EC into national pre- and post- service training curricula for all providers,

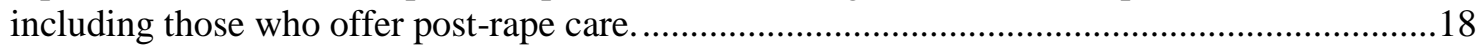

Expand training curricula to include the social context of EC provision, and all forms of EC. ......18

Target young women with high-impact awareness creation activities such as television

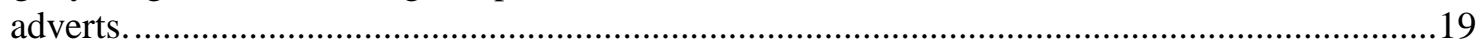

Encourage greater EC access through private sector pharmacy provision.....................................19 


\section{LIST OF TABLES}

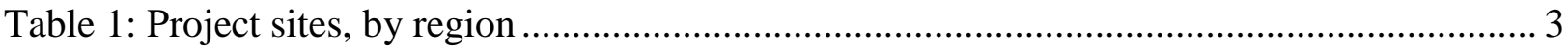

Table 2: Small Student Research Grants on EC ..................................................................... 4

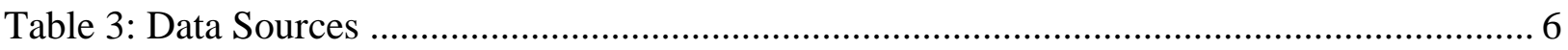

Table 4: Top 5 Study Clinics with the Highest Number of EC Units Distributed $n=3999 \ldots \ldots \ldots . .8$

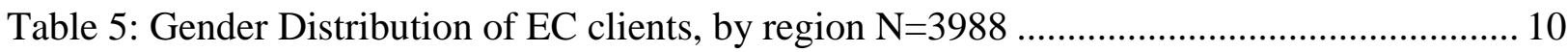

Table 6: Attitudes toward EC and other reproductive health service provision to adolescents

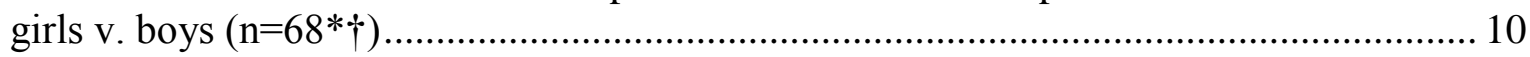

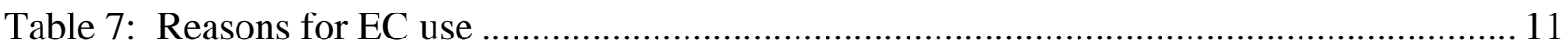

Table 9: Percent distribution of providers who offered specific EC services, by training

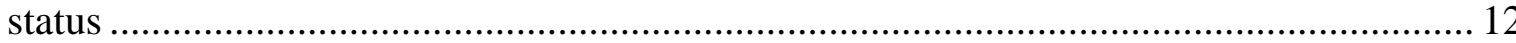

Table 10: Percent distribution of clients and providers who reported knowledge of specific

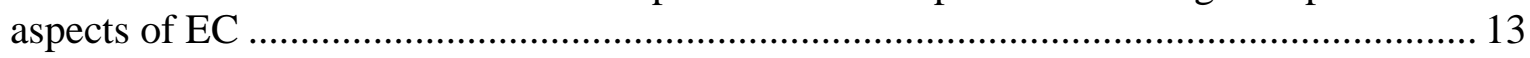

Table 11: Percent distribution of clients and providers by perceived appropriateness of EC*... 13

Table 12: Perceived Social and Health Problems Associated with Using EC ........................... 15

Table 13: Sources of EC Information for Clients and Providers, Provider and Client KAP

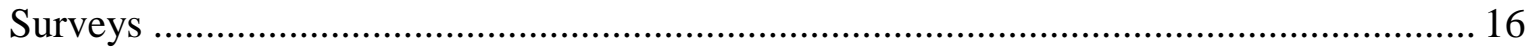

Table 14: Percent distribution of clients and providers by where they felt EC should be made available, Client and Provider KAP Surveys* ...................................................... 16

Table 15: Distribution of clients and providers by the amount of money (in Ethiopian Birr) they would be willing to pay for one dose of EC, Client and Provider KAP Surveys ....... 17

\section{LIST OF FIGURES}

Figure 1: Number of EC Units distributed in all Project Sites, May 2005- December 2006........ 7

Figure 2: Number of EC Units distributed, by region, May 2005 to December 2006 ................. 8

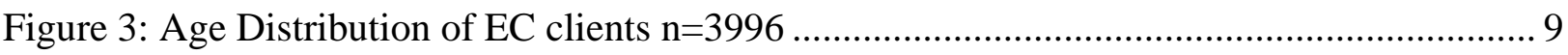

Figure 4: Sources of EC, Client KAP Survey* $(\mathrm{N}=150)$ Clients were most concerned about possible effects of using EC on future fertility and HIV prevalence.............................. 15 


\section{EXECUTIVE SUMMARY}

Building on nearly a decade of momentum, the Ethiopian Ministry of Health, the Ethiopian Society of Obstetricians and Gynecologists and ECafrique launched a two-year project in 2004 to mainstream emergency contraception (EC) in the country's public sector. The project aimed at improving reproductive health care among young women and reducing the country's abortion rate by expanding access to EC in the country. Overall, its goal was to demonstrate the feasibility of integrating EC within the public sector's broader contraceptive mix, and was guided by the following objectives:

- To scale-up and promote public sector EC services in five of the most populated regions of Ethiopia: Addis Ababa, Amhara, Oromia, Tigray, and the Southern Nations and Nationalities Peoples Region (SNNPR).

- To document the characteristics and use patterns of EC clients in the public sector.

- To introduce Postinor 2 as the first ever dedicated EC pill registered for use in Ethiopia.

To achieve these objectives, the project undertook a set of activities aimed at improving provider competency, increasing public demand and ensuring commodity security. By the conclusion of the project, 33 government and NGO facilities had begun providing Postinor 2 and 190 providers from those facilities were trained on EC using a curriculum developed specifically for the Ethiopian context. Broader awareness of the method was encouraged through small grants for student research on EC and a mass media campaign was launched to educate the public. The project also served as the field trial for registering one brand of EC pill, Postinor 2, which was officially approved for use in the country in December 2006.

Results of the final project evaluation, detailed in this report, demonstrate the project's success. Service statistics show that EC utilization steadily increased throughout the implementation period, and data from provider and client surveys provide insight into the attitudes and issues influencing EC access. Key findings include:

- EC users are primarily unmarried women between the ages of 20-24, although male partners are increasingly involved in EC decision-making and procurement. This runs counter to predominant perceptions of EC users as adolescent girls.

- Sexual assault is the least commonly cited reason for EC use, reflecting its current positioning as primarily a family planning method.

- Television advertisements and clinic-based health education were the most successful forms of communication on EC, while print media reached the fewest respondents.

- Both clients and providers believe that pharmacy provision of EC is socially acceptable, and agree that 1 Birr is the optimal price for sale in the private sector.

Ethiopia is currently poised to scale-up this mainstreaming effort with a view to effectively introducing EC as a core component of its family planning and post-rape care services nationwide. The findings and recommendations in this report are intended to inform and guide this scaling-up process. 


\section{BACKGROUND}

Recognition of the need to introduce EC into the public sector began in 1997, when the National Reproductive Health Needs Assessment noted that emergency contraception could play a critical role in "limiting unwanted pregnancy, reducing the need for unsafe abortion; ... lowering rates of maternal morbidity and ... [providing] an additional tool for rape management." It identified youth as the population most likely to access EC and a range of other coital-dependant methods ${ }^{2}$, due to their "irregular, unplanned, hurried and clandestine" sexual activity. The Assessment also found that access to family planning services was limited by providers who were perceived to be "out of touch" with the needs and concerns of their young clients. The Assessment report concluded that adolescents were less likely to access the type of regular or long-term contraceptive methods offered at government facilities thereby increasing their risk for unwanted pregnancy.

The next year, Ethiopian delegates attended an international conference in Malawi on emergency contraception where they developed a framework for introducing EC services in their country. This framework called for the establishment of a multisectoral advisory body and the integration of EC into ongoing training programs and national family planning guidelines. ${ }^{3}$ Shortly thereafter, the 1999 annual meeting of the Ethiopian Society of Obstetricians and Gynecologists (ESOG) endorsed EC's ability to "reduce dramatically the country's soaring levels of unsafe abortion" ${ }^{4}$.

\section{The Coital-Dependent Methods Study}

Building on this momentum, the Family Guidance Association of Ethiopia (FGAE) and the Population Council launched the Coital Dependent Methods Study (CDM) in 2001. The CDM study was designed to increase young people's access to coital-dependent methods by improving supply at the facility level and generating demand within the community. ${ }^{5}$

Working within FGAE's national network of youth-friendly clinics, the project developed a "branded" range of post-coital methods and trained providers on their provision. A single, youth-oriented graphic (pictured below) was included on repacked female condoms, male condoms and vaginal foaming tablets. Because no dedicated EC pill existed at the time in Ethiopia, FGAE employed the Yuzpe regimen of EC. Each packet contained four tablets of high-dose, combined oral contraceptives, simple instructions (in Amharic) on correct use, and two male condoms to encourage dual protection. By mid2003, 5,000 units of EC had been distributed to selected FGAE youth centers nationwide.

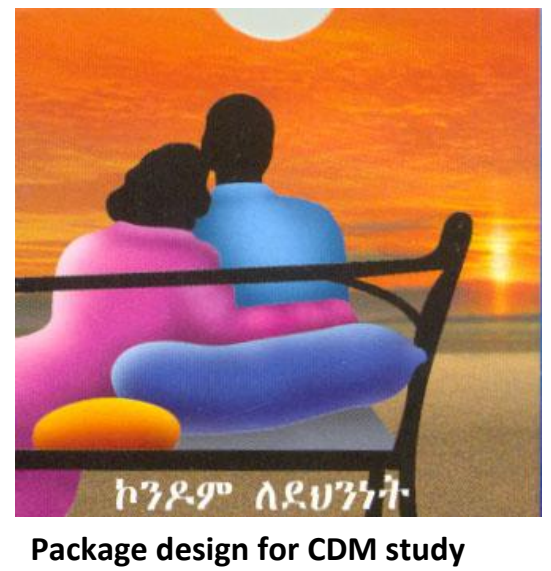

\footnotetext{
${ }^{1}$ Ethiopian Ministry of Health, Family Health Department (1999). An Assessment of Reproductive Health Needs in Ethiopia. Research on the Introduction and Transfer of Technologies for Fertility Regulation. Geneva: WHO, Special Programme of Research, Development and Research Training in Human Reproduction. WHO/HRP/ITT/98.1

${ }^{2}$ Coital-dependant methods include: male condoms, female condoms, vaginal forming tablets and emergency contraception.

${ }^{3}$ Margaret Sanger Center International. (April 1999). Strengthening Reproductive Health through Emergency

Contraception: Lilongwe Malawi 15-18 November 1998. New York: Margaret Sanger Center International.

${ }^{4}$ Proceedings of the VII Annual Conference of the Ethiopian Society of Obstetricians and Gynecologists. 17-18 May 1999.

Addis Ababa, Ethiopia. pp. 17-26

${ }^{5}$ For more information on this project, see: Rumbold, V. and Skibiak, J. (2006). Expanding Access to Coital-dependent Methods and Dual Protection within Youth-Centered Sexual and Reproductive Healthcare Facilities in Ethiopia. Unpublished Final Project Report. Nairobi: Population Council.
} 
To increase the demand for these products, the project recruited and utilized a network of Peer Service Providers (PSPs). The PSPs were trained in the provision of family planning services with emphasis on coital-dependent methods, adolescent sexuality and reproductive behavior, and youth-relevant IEC and counseling methodologies.

The CDM study found that provision of services was directly correlated with product availability: providers were more likely to dispense the methods when supplies were available and hoard when supplies were low. The repackaged supplies proved popular among clients and providers alike, although the associated production costs were unsustainable.

The study also demonstrated that untrained health care providers had limited familiarity with EC and held some misconceptions regarding its use. Most were aware that oral contraceptive pills could be used for emergency purposes, though knowledge of type, dosage and timing was low. The baseline study found that only $28 \%$ of the providers 1053 surveyed had ever administered EC and almost half believed its use would lead to increased promiscuity. Less than half (44\%) were aware of EC's three-day efficacy period.

Although the study demonstrated the potential role of the NGO sector in addressing the demand for EC, NGOs accounted for only about 15 percent of all family planning services delivered in Ethiopia. For most Ethiopians, therefore, EC still remained inaccessible: its provision did not appear in the standard training curricula for nurses, midwives, or other front-line health care workers, and no dedicated EC pills were available in the country.

\section{Mainstreaming EC in Ethiopia's Public Sector}

Building on the lessons learned from the CDM study, the Ministry of Health (MOH) Family Health Department and ESOG launched a two-year pilot project in early 2004 to mainstream $\mathrm{EC}$ in public sector facilities. Initially designed as an 18-month effort, the project was extended to December 2006 due to instability related to the country's 2005 elections. It was funded by the Concept Foundation, with additional financial and technical support provided by ECafrique.

The overall goal of the project was to demonstrate the feasibility of integrating EC within the public sector's broader contraceptive mix. Its objectives were to:

- Scale-up and promote public sector EC services in Ethiopia's five most populated Regions: Addis Ababa, Amhara, Oromia, Tigray, and the Southern Nations and Nationalities Peoples Region.

- Document the characteristics and use patterns of EC clients in the public sector.

- Introduce Postinor 2 as the first ever dedicated EC pill registered for use in Ethiopia.

The project undertook a set of activities that focused on increasing the availability of EC in select MOH facilities and creating awareness among potential clients. Study coordinators based in the nation's three leading medical schools (Addis Ababa, Gondar, and Jimma Universities) oversaw activities in each region. 


\section{Clinic-based service provision}

EC was provided in 33 facilities in five regions of the country (Table 1). Seven of these facilities were NGO clinics, representing areas where these NGOs dominate reproductive health service provision. Site selection was based on criteria that included monitoring capacity and overall functionality, and was made in collaboration with the regional study coordinators.

After provider training, an initial allotment of 10,000 units of Postinor 2 was allocated among the facilities. Product usage was monitored at each of the 33 participating hospitals and health centers, and additional supplies were delivered as needed.

Table 1: Project sites, by region

\begin{tabular}{|c|c|c|c|}
\hline Region & Health Facility & Region & Health Facility \\
\hline \multirow[t]{4}{*}{$\begin{array}{l}\text { Addis Ababa } \\
\text { (16 facilities) }\end{array}$} & \multirow{4}{*}{$\begin{array}{l}\text { Tikur Anbessa Hospital } \\
\text { Zewditu Hospital } \\
\text { St. Paul's Hospital } \\
\text { Yekatit } 12 \text { Hospital } \\
\text { Ghandi Hospital } \\
\text { Meshualekiya Health Center } \\
\text { Kolfe Health Center } \\
\text { Gulele Health Center } \\
\text { Lideta Health Center } \\
\text { Teklehaimanot Health Center } \\
\text { Woreda } 23 \text { Health Center } \\
\text { Woreda } 19 \text { Health Center } \\
\text { Yeka Health Center } \\
\text { FGAE Main Clinic } \\
\text { Marie Stopes Obstetric Center } \\
\text { Kirkos Health Center }\end{array}$} & $\begin{array}{l}\text { Amhara } \\
\text { (5 facilities) }\end{array}$ & $\begin{array}{l}\text { Gondar Hospital } \\
\text { Gondar Health Center } \\
\text { Azezo Health Center } \\
\text { Teda Health Center } \\
\text { FGAE Clinic }\end{array}$ \\
\hline & & $\begin{array}{l}\text { Oromiya } \\
\text { (4 facilities) }\end{array}$ & $\begin{array}{l}\text { Jimma Hospital } \\
\text { Jimma Health Center } \\
\text { FGAE Clinic } \\
\text { Marie Stopes Clinic }\end{array}$ \\
\hline & & $\begin{array}{l}\text { Tigray } \\
\text { (4 facilities) }\end{array}$ & $\begin{array}{l}\text { Mekele Hospital } \\
\text { Mekele Health Center } \\
\text { Kasetch Health Center } \\
\text { Semen Health Center }\end{array}$ \\
\hline & & $\begin{array}{l}\text { SNNPR } \\
\text { (4 facilities) }\end{array}$ & $\begin{array}{l}\text { Yirgalem Hospital } \\
\text { Awassa Health Center } \\
\text { FGAE Clinic } \\
\text { Marie Stopes Clinic }\end{array}$ \\
\hline
\end{tabular}

\section{In-service provider training}

As identified in the CDM study, correct knowledge of EC among Ethiopian service providers was low. To ensure quality services, the study undertook efforts to train providers in each of the participating facilities. A total of 69 doctors and nurses were trained to provide EC during the first round of training in early 2004. In late 2006, 121 providers participated in a second round of training intended to promote the sustainability of EC services after the project's conclusion.

Trainings were conducted by members of ESOG, using a manual developed specifically for the project. This manual was drafted by a team of ten experts from partner organizations, and was adopted at a national expert review workshop. It was based on materials produced by the Population Council in Bangladesh, and modified to reflect the specific needs and knowledge of Ethiopian service providers. ${ }^{6}$ The manual was pre-tested in Addis Ababa before being endorsed by the $\mathrm{MOH}$.

\footnotetext{
${ }^{6}$ Emergency Contraceptive Pills: A Training Manual (December 2005). New Delhi, India: Population Council.
} 


\section{Pre-service provider training}

In addition to conducting in-service training, the also project worked to build interest among students by offering small grants for degree-related research on EC. A call for proposals was issued to all medical, nursing or community health students at the country's most prominent universities (Addis Ababa, Gondar and Jimma Universities) in early 2006. Study coordinators at each site mentored students in conducting the research and ECafrique provided funding for the field work. A total of ten projects were selected through the national competition, which examined EC in the context of social and medical issues such as sexual assault, pharmacy provision and adolescent access (Table 2). EGOG will publish the results of these research projects in a special issue of the Ethiopian Journal of Reproductive Health.

Table 2: Small Student Research Grants on EC

\begin{tabular}{|l|l|l|}
\hline Study Description & Principal Investigator & University and department \\
\hline \hline $\begin{array}{l}\text { EC knowledge, attitudes and practice } \\
\text { (KAP) survey of secondary school girls in } \\
\text { Gondar }\end{array}$ & Awol Hussein & $\begin{array}{l}\text { Gondar University, Community } \\
\text { Health }\end{array}$ \\
\hline EC KAP survey of university women & Hiwot Abera & Jimma University, Nursing \\
\hline $\begin{array}{l}\text { Police perceptions of EC and sexual } \\
\text { assault services }\end{array}$ & Munir Kassa & $\begin{array}{l}\text { Addis Ababa University, } \\
\text { Obstetrics and Gynecology }\end{array}$ \\
\hline $\begin{array}{l}\text { KAP survey of abortion clients' } \\
\text { experience with EC and contraception }\end{array}$ & Anteneh Admasu & $\begin{array}{l}\text { Jimma University, Public } \\
\text { Health }\end{array}$ \\
\hline $\begin{array}{l}\text { KAP survey of post-abortion care clients } \\
\text { KAP survey of pharmacist's experience } \\
\text { with EC provision }\end{array}$ & Berhanu Dessalegn & $\begin{array}{l}\text { Addis Ababa University, } \\
\text { Obstetrics and Gynecology }\end{array}$ \\
\hline $\begin{array}{l}\text { Mixed methods research on EC and } \\
\text { sexual assault }\end{array}$ & Feleke Worku & $\begin{array}{l}\text { Addis Ababa University, } \\
\text { Obstetrics and Gynecology }\end{array}$ \\
\hline $\begin{array}{l}\text { EC KAP of secondary school girls in } \\
\text { Jimma }\end{array}$ & Tadesse Alemu & $\begin{array}{l}\text { Addis Ababa University, } \\
\text { Obstetrics and Gynecology }\end{array}$ \\
\hline $\begin{array}{l}\text { EC KAP survey of university women } \\
\text { EC KAP survey of hospital-based } \\
\text { physicans }\end{array}$ & Yonas Tesfanesh & $\begin{array}{l}\text { Jimma University, Nursing } \\
\text { Obstetrics and Gynecology }\end{array}$ \\
\hline
\end{tabular}

To support this research, ECafrique compiled a comprehensive CDcompendium of EC training and reference materials that was distributed widely among students and faculty at the participating universities It included $\mathrm{n}$ annotated bibliography of relevant research and reference materials on EC as well as the full-texts of many documents. Due to its popularity, an international version was also developed for global distribution.

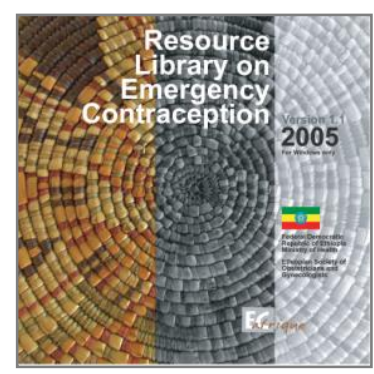




\section{Awareness creation and advocacy}

The project undertook a series of media activities intended to generate demand for the services at the community level and ensure sustained political support. A professional journalist was recruited by ESOG to oversee this work.

Under the direction of the journalist, a mass media campaign was conducted throughout 2006. The campaign targeted opinion leaders and potential urban middle and upper class clients, and included:

- A one-minute informational television commercial on EC featuring locally popular young adult actors.

- An interview with the project coordinator on the regular women's television talk show, Kesetoch Admass. The 60minute interview, which aired in 20-minute installments for 3 consecutive weeks, focused on EC and its impact on the prevention of unsafe abortion as a way of reducing the country's high maternal mortality and morbidity rates.

- A series of short informational news spots in leading national media e.g. Addis Admass (weekly newspaper) and Lanchi ina Lante (radio program), which highlighted the importance of $\mathrm{EC}$ in a variety of situations.

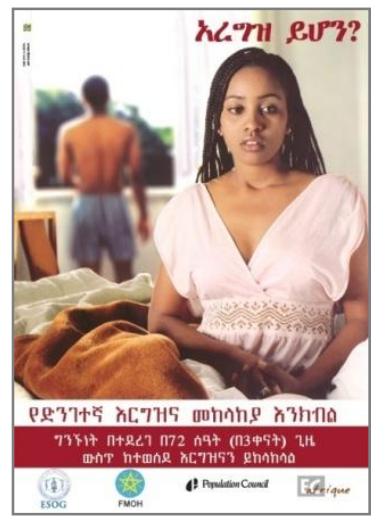

Other outreach efforts entailed:

- Supporting the inclusion of EC into regular facility-based client health education sessions.

- Developing and distributing a youth-oriented poster (shown), which communicated key messages about EC use and timing in the national language, Amharic.

\section{Postinor 2 Registration}

To ensure continued commodity supplies, a key component of the project was the introduction and registration of a dedicated EC pill in the country. As a first step, ESOG obtained authority to import Postinor 2 into the country for use by the project. Permission was granted by the Ethiopian Drug Administration and Control Authority (DACA) in August 2004 and 40,000 units of Postinor 2 were procured using funds made available by ECafrique. The consignment was delivered to the Ministry of Health's storehouse in December 2004, and subsequently distributed to the 33 intervention sites.

In addition to scaling-up EC services in the public sector, the project was intended to serve as the "field test" required for registration of Postinor 2. Working with the local pharmaceutical company Beker, ESOG and ECafrique secured product registration based on the success of this project. In December 2006, DACA officially approved Postinor 2 for use in Ethiopia's public and private sectors. 


\section{Evaluation Methodology}

To evaluate the impact of the project, three sets of data were collected (Table 3). First, basic service statistics, including basic client profiles, were recorded for every client who received Postinor 2 in each of the 33 project sites between May 2005 and December 2006. A total of 3,999 cases of EC use were reported during the 20 months of service provision.

Second, toward the conclusion of the project period, providers were interviewed to assess their experiences with EC. A knowledge, attitudes and practice (KAP) survey was conducted with 121 providers from the five regions participating in the project in October and November 2006. The survey was self-administered and was completed by all providers who attended the second training exercise, and was distributed immediately before the commencement of training. The bulk of these respondents were nurses (73\%) followed by midwives (14\%); only three doctors were included in the survey.

Third, a client KAP survey was conducted in neighboring health facilities in Addis, Jimma and Awassa in the week following the provider survey. A total of 768 health clinic center clients were interviewed by nurses who completed the EC training. No nurses were assigned to collect data from the facilities they normally worked in. Respondents comprised all clients and companions, male and female, who presented at the clinic during the week-long data collection period. Interviewers were stationed throughout the facility in order to capture a diverse sample of clients. They were instructed to approach clients only at the end of their visit, and to obtain written consent before commencing the interview. The survey sought general information on client contraceptive attitudes and practices as well as awareness and perceptions of EC. The sample was intended to serve as a proxy for awareness among the segment of the population that is most likely to seek institutionalized health care services.

Table 3: Data Sources

\begin{tabular}{|l|c|c|c|}
\hline \multirow{2}{*}{ Region } & \multicolumn{3}{|c|}{ Number of Respondents/Cases } \\
\cline { 2 - 4 } & Service Stats & Provider KAP & Client KAP \\
\hline \hline Addis Ababa & 2659 & 58 & 205 \\
Oromiya & 194 & 22 & 283 \\
Amhara & 271 & 16 & $\mathrm{n} / \mathrm{a}$ \\
SNNPR & 478 & 14 & 280 \\
Tigray & 397 & 11 & $\mathrm{n} / \mathrm{a}$ \\
TOTAL & 3999 & 121 & 768 \\
\hline
\end{tabular}

The data were entered into Epi-Info by ESOG staff in Addis Ababa, with support from ECafrique. Analysis was done using SPSS; a chi-square test was used to measure the strength of association in bivariate relationships. 


\section{PROJECT OUTCOMES: EC UPTAKE}

By the end of the project in December 2006, a number of key achievements had been realized. Specifically, EC had been successfully integrated into the method mix in the intervention sites, providers demonstrated adequate knowledge of EC, and ESOG's media activities had begun to shape public opinion about the method. Nonetheless, while there was an overall increase in EC uptake, this was not uniform across project sites.

\section{EC can be effectively integrated into Ethiopia's public sector method mix}

Service statistics indicate that EC services can be successfully integrated into the country's public health sector. Utilization of EC increased steadily throughout the project period, with almost 600 units distributed by the project's final month (Figure 1).

Figure 1: Number of EC Units distributed in all Project Sites, May 2005- December 2006

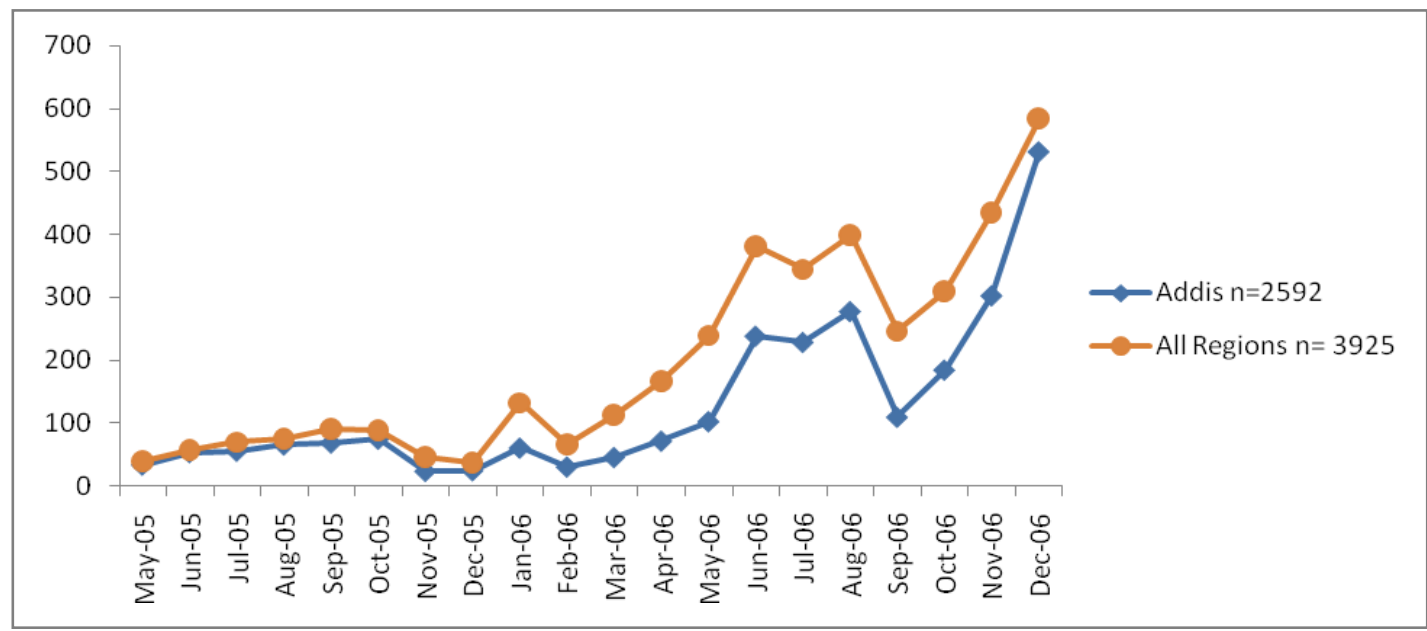

Source: service statistics

\section{Project performance varied widely across the regions}

Much of the increase in the uptake of EC was due to trends in Addis Ababa, where nearly half of the study sites were located (figure 1). Overall, $67 \%$ of all EC units distributed by the project were through facilities in Addis Ababa.

A much less distinct picture emerges for the other regions. While utilization in each region increased during the life of the project, the trend was by no means consistently upward (Figure 2). This suggests that either the demand was more consistent in Addis Ababa or the program was not uniformly implemented across the five participating regions. Program managers believe that the latter is the case, as supplies and supervision posed greater challenges outside of the capital. 
Figure 2: Number of EC Units distributed, by region, May 2005 to December 2006

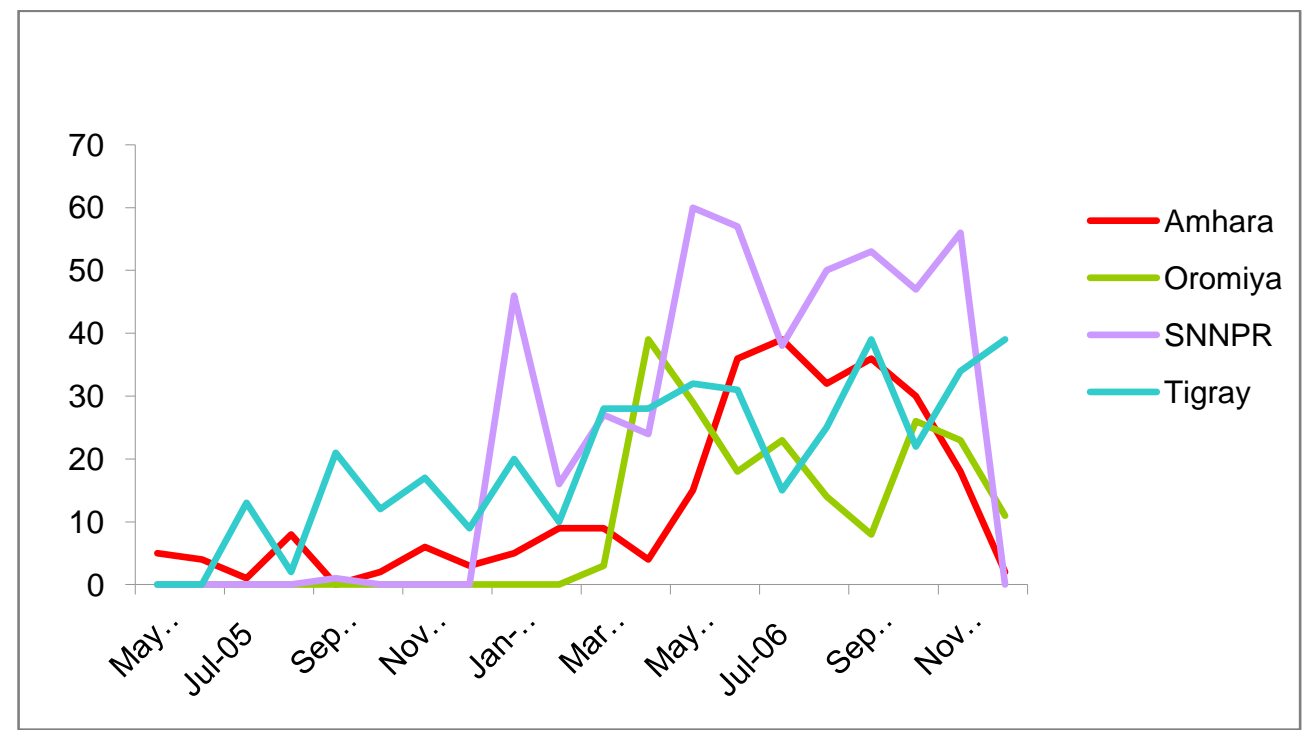

Source: service statistics

\section{FGAE clinics involved in the CDM study were among the highest performing facilities}

Two of the five highest performing clinics were also sites for the CDM study, which as noted above, was the first attempt to introduce EC into Ethiopia (Table 4). It is likely that continued client demand and provider knowledge at the two FGAE youth clinics located in Addis Ababa and Awassa bolstered utilization during the present study. To the extent that this is the case, it highlights the cumulative effect of such interventions on increasing awareness of EC.

Table 4: Top 5 Study Clinics with the Highest Number of EC Units Distributed $n=3999$

\begin{tabular}{|l|l|l|l|}
\hline Facility Name & Region & Units Distributed & $\%$ of total units \\
\hline \hline FGAE AA & Addis Ababa & 987 & 24.7 \\
Marie Stopes & Addis Ababa & 378 & 9.5 \\
FGAE Awassa & SNNPR & 389 & 9.7 \\
Mekele Health Center & Tigray & 264 & 6.6 \\
Gandhi Mem. Hosp. & Addis Ababa & 218 & 5.5 \\
\hline
\end{tabular}




\section{Project Outcomes: Client Characteristics and Context OF EC USE}

Client characteristics and context of EC use do not support conventional perceptions of EC users as adolescent girls or rape survivors.

\section{The bulk of EC clients were unmarried women between the ages of 20-24}

Contrary to popular perception, service statistics showed that adolescents were not the primary users of EC. Rather, most users (71\%) were young adults aged between 20 and 29 years (Figure 3). Almost half (47\%) of the clients were aged between 20 and 24 years while younger adolescents (aged 19 years and below) comprised only 20\%. A similar age distribution is found in the client KAP survey: of the 20 clients who reported having ever used EC, 14 (70\%) were between the ages of 20 and 29 years.

Figure 3: Age Distribution of EC clients $n=3996$

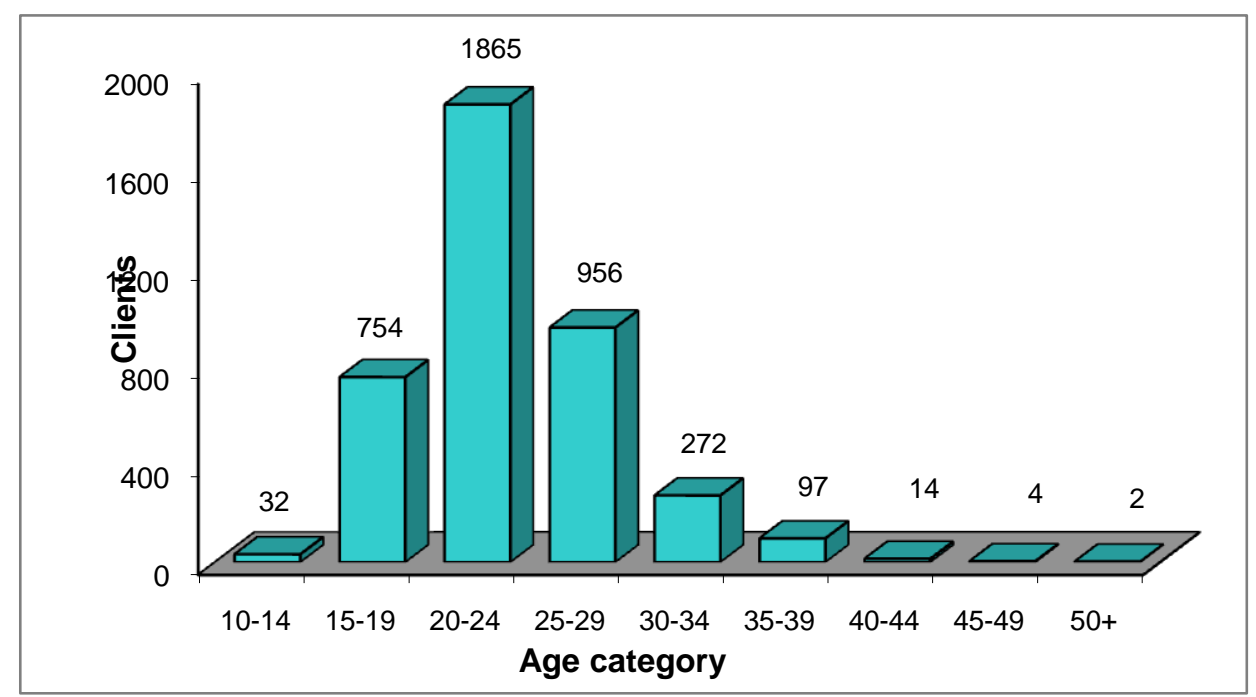

Source: service statistics

A substantial proportion of these users (41\%) were married. This proportion was even higher when disaggregated by region; in Tigray for example, 55\% of the clients reported that they were married. This is similar to the pattern observed in the client KAP survey in which 11 of the 20 of those who had ever used EC identified themselves as married. This could partly reflect the fact users tended to be older and therefore more likely to be married, but it could also be due to clients incorrectly identifying themselves as married in order to avoid the stigma associated with sex outside of marriage.

\section{Men were actively involved in their partner's decision to use EC}

Whereas women constituted the majority of clients (96\%), some men also obtained EC for their partners. A total of 173 men accessed EC during the study period, and in Oromiya, nearly $22 \%$ of all EC clients were men (Table 5). 
Table 5: Gender Distribution of EC clients, by region $\mathrm{N}=3988$

\begin{tabular}{|l|c|c|c|}
\hline Region & \# male clients & \# female clients & \% male clients \\
\hline \hline Oromiya & 42 & 152 & $21.6 \%$ \\
SNNPR & 30 & 448 & $6.3 \%$ \\
Addis Ababa & 98 & 2558 & $3.7 \%$ \\
Amhara & 2 & 261 & $0.7 \%$ \\
Tigray & 1 & 396 & $0.2 \%$ \\
\hline Overall & 173 & 3815 & $4.3 \%$ \\
\hline
\end{tabular}

Source: Service Statistics

The client KAP survey provides further indication of male involvement in EC use. According to the 20 women who identified themselves as EC users, nearly half (45\%) had talked to their partners before making the decision to use the method. Furthermore, almost two-thirds (61\%) informed their partners before using the method, and in all cases it was reported that their partners supported their decision.

The provider KAP survey, however, also shows an unwillingness to deliver EC services to male clients ${ }^{7}$. Providers were significantly more likely to report a preference to deliver EC services to adolescent girls than to adolescent boys (Table 6). Providers trained by ESOG were no more likely than their untrained counterparts to report such a preference, implying that gender issues are not sufficiently addressed in the EC curriculum.

Table 6: Attitudes toward EC and other reproductive health service provision to adolescents girls $v$. boys $\left(n=68^{*} t\right)$

\begin{tabular}{|l|c|c|c|}
\hline & $\begin{array}{c}\text { Girl scenario } \\
\%\end{array}$ & $\begin{array}{c}\text { Boy scenario } \\
\%\end{array}$ & p-value \\
\hline \hline Provide EC & 91.5 & 41.2 & 0.019 \\
Provide FP advice & 63.6 & 47.1 & 0.000 \\
Provide STI/HIV counseling & 38.1 & 50.0 & 0.000 \\
Provide condoms & 23.7 & 32.4 & 0.000 \\
Advise against adolescent sex & 11.0 & 13.2 & 0.000 \\
Do nothing/ Refuse EC & 0.0 & 7.4 & n/a \\
\hline
\end{tabular}

*multiple responses allowed

$\dagger$ Only providers who had dispensed EC at least once were asked this question

Source: provider KAP

Provider attitudes toward male access are incongruous with client behaviors. As Table 5 indicates, men are a small, but important, segment of the EC clientele; table 6, however, demonstrates that providers are less likely to provide male clients with the full range of reproductive health services and information that EC users require.

\footnotetext{
${ }^{7}$ Providers were asked how they would respond to an unmarried adolescent girl who claimed to have engaged in unprotected sex two days prior and was seeking advice on how to avoid a pregnancy and that of an unmarried adolescent boy in a similar situation who wanted to obtain EC pills for his girlfriend.
} 


\section{EC is most frequently used after unprotected sex, rarely after sexual assault}

All three data sources indicate that clients most frequently sought EC after engaging in "unprotected sex" (Table 7). Although the provider KAP allowed multiple responses, the trend across all the data sources demonstrates that contraceptive failure is the second most frequent reason for use, followed by sexual assault.

Table 7: Reasons for EC use

\begin{tabular}{|l|c|c|c|}
\hline & $\begin{array}{c}\text { Service statistics } \\
\mathbf{n = 3 9 4 6} \\
\mathbf{( \% )}\end{array}$ & $\begin{array}{c}\text { Client KAP } \\
\mathbf{n = 2 0} \\
(\%)\end{array}$ & $\begin{array}{c}\text { Provider KAP } \\
\mathbf{n = 6 6 ^ { * }} \\
\mathbf{( \% )}\end{array}$ \\
\hline \hline Unprotected sex & 81.4 & 84.6 & 80.3 \\
Contraceptive failure & 14.2 & 15.4 & $42.4^{\dagger}$ \\
Sexual assault & 4.4 & 0.0 & 37.9 \\
\hline
\end{tabular}

*reasons for use among last $3 \mathrm{EC}$ clients, multiple responses allowed

† condom breakage

Clinic records further indicate that only 172 of the 3999 doses of EC were administered to survivors of sexual assault, while providers reported that more than one in every three clients experienced sexual assault. Due to the limited number of responses, the meaning of this data is unclear, although it may represent a providers' recall bias in favor of more memorable sexual assault cases or their reluctance to record such cases in clinic records. Reflecting patterns across the continent ${ }^{8}$, the survivors recorded in the service statistics were young, with $52 \%$ of all cases being between the ages of 10 and 19. Among the very young adolescents (between 10 and 14 years old), sexual assault comprised nearly $70 \%$ of the cases.

\section{Repeat use of EC is low, and providers are successful at "bridging" clients to other reproductive health services.}

In countries such as Kenya and Botswana, where EC is more widely available, concerns have emerged over its use as a regular family planning method. Because it is less effective than other modern methods of contraception and does not offer protection against HIV and other sexually transmitted infections (STIs), the World Health Organization recommends EC only for use as a back-up method ${ }^{9}$. Data from the client KAP survey indicate that repeat use is not currently a problem in Ethiopia. Of the 17 clients who reported on frequency of use, the bulk (15) noted that they had only taken EC once in the past year (Table 8).

Table 8: Percent distribution of EC users by frequency of use and indicators of 'bridging'

\begin{tabular}{|l|c|c|}
\hline & $\begin{array}{c}\text { Client KAP } \\
\mathbf{n}=17 \\
\text { (\%) }\end{array}$ & $\begin{array}{c}\text { Provider KAP* } \\
\text { n=65 } \\
\text { (\%) }\end{array}$ \\
\hline \hline Used EC only once in the past year & 88.2 & n/a \\
Began using a new or different contraceptive method after EC & 55.5 & 56.1 \\
Were provided any of the following services alongside EC & \\
Provided with family planning advice & 92.3 & 69.2 \\
Referred to HIV/VCT services & 15.4 & 56.9 \\
Referred sexual assault survivor to police & 0.0 & 15.4 \\
\hline
\end{tabular}

\footnotetext{
* services provided to the last 3 clients

$\dagger^{\dagger}$ multiple responses were allowed in both surveys
}

\footnotetext{
8 “Sexual and Gender-based Violence in Africa: Key Issues for Programming." February 2008. Nairobi: The Population Council.

${ }^{9}$ When used within 72 hours of unprotected sex, EC reduces the risk of pregnancy by at least $75 \%$. (Medical Eligibility Criteria for Contraceptive Use, Third Edition (2004). Geneva: World Health Organization.
} 
The moment of EC provision also allows the opportunity to respond to the client's other reproductive health needs. Although the ESOG training curriculum did not explicitly address such "bridging" to other services, the client and provider KAP surveys suggest that it did take place within study sites. Nearly half of all EC clients adopted a different or new contraceptive method following EC use, most likely because providers routinely counseled them on more reliable methods (Table 8). Interestingly, there was no significant difference in "bridging" among providers who were trained in EC and those who were not, indicating that this behavior was not directly influenced by ESOG training.

\section{Project outcomes: Provider capacity}

Provider training and experience are at the core of quality EC service delivery. While overall levels of knowledge were high among all providers, those who had received formal training on EC were more likely to hold accurate and positive attitudes toward its provision.

Few providers were trained on EC, although many more had experience with the method As noted above, the provider KAP survey was conducted immediately before a one-day training on EC. At that point, only one-third (33\%) of all providers had received prior instruction on EC. Of these, most (85\%) reported that they were trained by ESOG under the current project. The remaining providers had been trained under the FGAE project; none indicated that they learned of EC during their professional training. This implies that in areas where the project was not implemented, it is unlikely that providers have received any instruction on EC.

\section{Trained providers were more likely to dispense and provide information on EC}

The majority of providers surveyed $(81 \%)$ had discussed EC with their clients, and those who received training on EC were more likely to provide it (Table 9). In addition, the majority of trained providers shared information on EC to all likely users even if they did not request it. This is confirmed in client reports, which listed provider interaction as the second most frequent source of information on EC.

Table 9: Percent distribution of providers who offered specific EC services, by training status

\begin{tabular}{|l|c|c|}
\hline & Trained (\%) & Untrained (\%) \\
\hline Have ever talked to a client about EC. & 97.4 & 71.0 \\
When do you provide information on EC? & & \\
$\quad$ To all likely users & 60.9 & 37.0 \\
Only when the client requests it & 39.1 & 52.2 \\
\hline
\end{tabular}

\section{Training had limited impact on providers' generally high knowledge of specific aspects of EC}

While training may have given providers more confidence to discuss EC with their clients, it did not significantly increase their knowledge of specific aspects of the method. Trained providers demonstrated only slightly higher knowledge of EC's mechanism of action and its 
timing than their untrained counterparts (Table 10) ${ }^{10}$. These figures do, however, indicate substantial improvements from the CDM baseline in which only $44 \%$ of providers correctly identified the three-day time limit for EC use. Interestingly, trained providers were slightly more likely to believe that EC induced abortion.

Table 10: Percent distribution of clients and providers who reported knowledge of specific aspects of EC

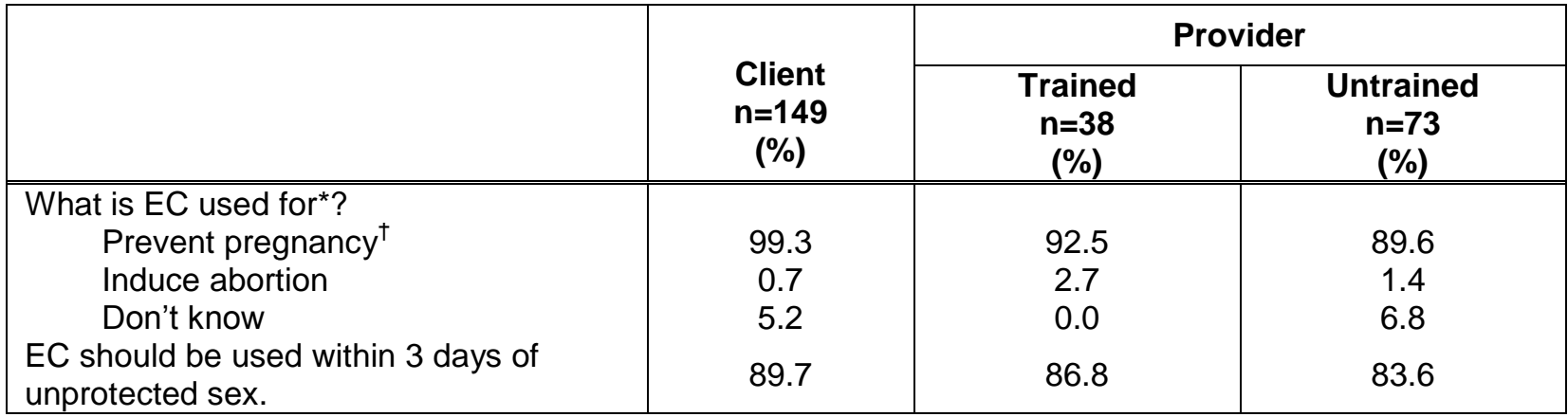

* Multiple responses allowed

$\dagger$ choice includes preventing implantation, inhibiting ovulation and preventing pregnancy

Source: Client and provider KAP surveys

\section{Providers were more conservative than clients in their perceptions of appropriate EC users}

Clients were much less conservative in identifying likely EC users than were providers (Table 11). Most of the clients believed that access should be extended to a wide range of women, whereas providers saw the need for greater restrictions. While no significant differences existed among trained and untrained providers, training did appear to improve perceptions of the types of clients who should receive EC.

Table 11: Percent distribution of clients and providers by perceived appropriateness of EC*

\begin{tabular}{|c|c|c|c|}
\hline & \multirow[b]{2}{*}{$\begin{array}{l}\text { Client } \\
\mathrm{n}=762 \\
(\%)\end{array}$} & \multicolumn{2}{|c|}{ Provider } \\
\hline & & $\begin{array}{c}\text { Trained } \\
\mathrm{n}=36 \\
(\%)\end{array}$ & $\begin{array}{c}\text { Untrained } \\
\mathrm{n}=75 \\
(\%)\end{array}$ \\
\hline \multicolumn{4}{|l|}{ Indications } \\
\hline Rape survivors & 96.3 & 97.2 & 92.0 \\
\hline Women experiencing contraceptive failure & 80.3 & 89.9 & 69.3 \\
\hline Contraindications & & & \\
\hline Pregnant women & 1.7 & 8.3 & 13.3 \\
\hline Post-menopausal women & 2.5 & 36.1 & 28.0 \\
\hline Appropriate Users & & & \\
\hline Adolescents & 76.0 & 63.9 & 53.3 \\
\hline Married women & 77.9 & 72.2 & 42.7 \\
\hline Unmarried women & 71.7 & 61.1 & 49.3 \\
\hline Women who have sex infrequently & 72.0 & 50.0 & 49.3 \\
\hline
\end{tabular}

*Multiple responses allowed

Source: Client and provider KAP surveys.

\footnotetext{
${ }^{10}$ In this project, EC was recommended for use within three days (72 hours) after unprotected sex. After its inception, the WHO revised the time limit for efficacy to 120 hours (5 days) after unprotected sex.
} 


\section{EC training and provision in Ethiopia is biased toward Postinor 2}

While this project focused on introducing Postinor 2, it is important to note that this is not the only brand of EC pill; nor is it the only type of post-coital contraception that can be offered. Both the Yuzpe method, which consists of high doses of oral contraceptive pills (OCPs), and intrauterine contraceptive devices (IUCDs) can be used as EC. Although the ESOG curriculum included these other methods, very few providers identified that they received instruction on the Yuzpe method or IUCDs for EC. When asked to identify all methods for preventing pregnancy following intercourse, only $49 \%$ of trained providers mentioned OCPs, 64\% reported IUDs, while an overwhelming 93\% identified Postinor 2.

Although this finding indicates the success of efforts to train providers on Postinor 2, it also highlights a potential over-reliance on a single brand of EC pill. In cases of commodity shortages or the introduction of competing brands, the bulk of providers lack the knowledge or skills necessary to administer alternative forms of EC.

\section{Project Outcomes: Public Awareness And Access}

Creating public awareness about EC was a key element of the project, which sought to introduce a new method into the country's reproductive health services. Data demonstrates that such activities had an impact on increasing awareness in the target populations, although overall knowledge still remains limited.

\section{EC use remains low, most likely due to limited awareness}

Despite the increased use of EC over the project period, the client KAP survey suggests that overall use still remains low. Only $20(0.2 \%)$ of the 768 women and men interviewed reported that they or their partners had ever used EC. In nearly all of these cases (18) Postinor 2 was used.

A key barrier to use remains limited awareness about the method, as only $20 \%$ of those interviewed stated that they had ever heard of EC. The majority of the clients (83\%) also indicated that information on EC was not widely available to women in their communities.

\section{Clients who were aware of EC demonstrated high levels of knowledge}

Although few respondents knew of EC, those who did were remarkably well-informed. As indicated in table 10, clients who were aware of the method demonstrated levels of knowledge that rivaled, and in some cases exceeded, trained providers. All but one client correctly identified EC as a method for preventing pregnancy, and nearly $90 \%$ knew that EC should be taken within 72 hours of unprotected sex to be effective.

These clients were also able to correctly identify EC access points (Figure 4). When asked where EC could be obtained, nearly all clients who were aware of EC cited the clinic where the survey was conducted. FGAE clinics were the second most known location, possibly reflecting the legacy of the CDM study. It is also interesting to note that while EC was not legally available for sale in private sector pharmacies prior to its introduction by the project, over $30 \%$ of respondents indicated that it could be obtained over the counter. 
Figure 4: Sources of EC, Client KAP Survey* $(\mathrm{N}=150)$ Clients were most concerned about possible effects of using EC on future fertility and HIV prevalence.

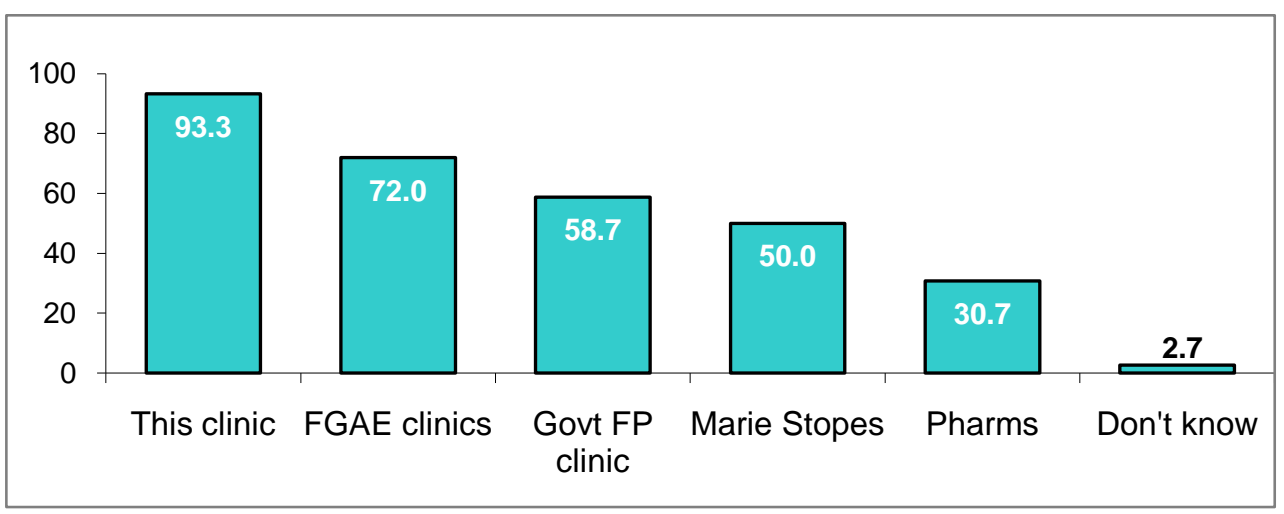

*Multiple responses allowed

While overall knowledge was high, some clients expressed concerns about the potential sideeffects of using EC. Of those who feared health problems, the largest proportion (41\%) believed that it could cause difficulties conceiving in the future (Table 12). Increases in HIV cases and in adolescent sexual activity were some of the possible social effects identified. These findings echo public concerns across the continent, and should be taken into consideration when designing information and advocacy messages.

Table 12: Perceived Social and Health Problems Associated with Using EC

\begin{tabular}{|c|c|c|}
\hline & \# of clients & $\%$ \\
\hline Can EC cause health problems $\mathbf{n}=\mathbf{7 6 1}$ & 73 & 9.6 \\
\hline What type of health problems?* $n=73$ & & \\
\hline difficulty conceiving & 30 & 41.1 \\
\hline causes indigestion & 21 & 28.8 \\
\hline menstrual irregularities & 14 & 19.2 \\
\hline nausea or vomiting & 13 & 17.8 \\
\hline may not work & 12 & 16.4 \\
\hline $\begin{array}{l}\text { Can easy access to EC cause social problems? } \mathbf{n}=768 \\
\text { What type of social problems?* } n=88\end{array}$ & 88 & 11.5 \\
\hline increases HIV cases & 54 & 61.4 \\
\hline encourages adolescent sex & 52 & 59.1 \\
\hline encourages promiscuity & 45 & 51.1 \\
\hline problems with family or husband & 10 & 11.4 \\
\hline
\end{tabular}

*Multiple responses allowed

Source: client KAP survey

\section{Television adverts and clinic-level outreach were the most successful outreach activities}

Nearly three-quarters of the clients who knew of EC learned of the method within the past year, which corresponds to the project's media outreach phase. Both clients and providers demonstrated similar exposure to the media campaign, suggesting that it reached a broad segment of the targeted urban populations. The ESOG television advertisement, which was aired during popular television dramas during the weeks prior to the survey, appears to have reached the widest audience. Although less effective, print media was most likely to reach providers, as was the topical Kesetoch Admas television feature (Table 13). 
Table 13: Sources of EC Information for Clients and Providers, Provider and Client KAP Surveys

\begin{tabular}{|l|l|l|}
\hline & $\begin{array}{l}\text { Client } \mathbf{n = 1 4 8} \\
(\%)\end{array}$ & $\begin{array}{l}\text { Provider } \mathbf{n = 1 2 1} \\
(\%)\end{array}$ \\
\hline \hline $\begin{array}{l}\text { First learned of EC within the past year. } \\
\text { Did you gain information from?* }\end{array}$ & 74.8 & $\mathrm{n} / \mathrm{a}$ \\
ESOG television ad & 49.3 & 40.8 \\
Health service provider & 23.6 & $\mathrm{n} / \mathrm{a}$ \\
ESOG weekly column in Lanchi ina Lante & 12.9 & 35.6 \\
Friends or family & 10.8 & $\mathrm{n} / \mathrm{a}$ \\
ESOG feature on Kesetoch Admas & 7.4 & 10.7 \\
ESOG weekly column in Addis Admas & 6.1 & 16.3 \\
\hline
\end{tabular}

* Multiple responses allowed

More conventional channels of health communication remained key in creating awareness about EC. Nearly $80 \%$ of all providers indicated that they included EC messages in their facility's regular health education sessions. These efforts may account for the fact that nearly one-quarter of those who knew of EC reported that they had first heard of it from their health provider.

\section{Broader access to EC is acceptable to the public}

To inform future scaling-up efforts, clients and providers were asked to identify the locations where they felt EC should be made available and the types of providers who should dispense it. Again, clients were more liberal in their perceptions of acceptable access than were providers. Providers tended to overwhelmingly identify conventional sources such as health centers, family planning clinics, and pharmacies (Table 14). Clients, on the other hand, supported expanded access for sexual assault survivors with over $80 \%$ mentioning emergency rooms and nearly $40 \%$ indicating police stations. They also supported community access through the new cadre of community-based reproductive health agents (CBRHAs) as well as expanded adolescent access through secondary schools.

Table 14: Percent distribution of clients and providers by where they felt EC should be made available, Client and Provider KAP Surveys*

\begin{tabular}{|l|c|c|}
\hline & $\begin{array}{c}\text { Client } \\
\mathbf{n = 7 6 4}(\%)\end{array}$ & $\begin{array}{c}\text { Provider } \\
\mathbf{n = 1 1 3}(\%)\end{array}$ \\
\hline \hline Health center & 98.0 & 96.5 \\
FP clinics & 84.6 & 92.0 \\
Emergency Rooms (ERs) & 83.9 & 28.3 \\
Pharmacies & 72.3 & 49.6 \\
Community level (CBRHAs) & 51.1 & 30.1 \\
Police stations & 38.1 & 17.0 \\
Secondary schools & 37.2 & 17.9 \\
\hline
\end{tabular}

*Multiple responses allowed

\section{One Birr is the optimal price for EC sales in pharmacies}

By the end of the project, Postinor 2 was approved for sale at private pharmacies. Previously, EC had only been provided at no cost in the project sites and at minimal cost in FGAE clinics. To assist pharmacists in pricing the new product, the survey also asked respondents to identify the amount of money (in Ethiopian Birr) that they would be willing to pay for EC in private pharmacies. The most commonly cited price was 1 birr (Table 15). 
Table 15: Distribution of clients and providers by the amount of money (in Ethiopian Birr) they would be willing to pay for one dose of EC, Client and Provider KAP Surveys

\begin{tabular}{|l|c|c|}
\hline & $\begin{array}{c}\text { Client } \\
\mathbf{n = 7 5 5}\end{array}$ & $\begin{array}{c}\text { Provider } \\
\mathbf{n = 9 8}\end{array}$ \\
\hline \hline free & 64 & 2 \\
$.50 \mathrm{birr}$ & 96 & 23 \\
1birr & 185 & 28 \\
2birr & 96 & 12 \\
3birr & 63 & 12 \\
4birr & 19 & 0 \\
5birr & 134 & 12 \\
$\geq 10 \mathrm{birr}$ & 98 & 9 \\
\hline
\end{tabular}

\section{CONCLUSIONS AND RECOMMENDATIONS}

Overall, the project achieved its major objectives. First, it introduced EC services in 33 public and NGO facilities in the country's five major regions, demonstrating a steadily increasing demand for these services. Second, it highlighted the current state of knowledge on EC and identified a set of emerging issues that may influence future service expansion efforts. Finally, it registered one brand of EC, Postinor 2, as the first dedicated product available in Ethiopia's public and private sector.

As a next step, it is necessary for the Ministry of Health to build upon these successes by continuing to expand access to EC across the country. The following recommendations are intended to help guide such efforts.

\section{Introduce EC as an essential element of the country's family planning method mix}

The key finding of this project is that EC can be successfully provided in Ethiopia's public sector family planning facilities. It demonstrates that a latent demand for the product exists and that such demand can be met within the context of current reproductive health programs. With the registration of Postinor 2 in late 2006, the product is now positioned to become a core element of the country's method mix and, once adequate stocks are procured, can be offered nationwide.

\section{Ensure that EC is also provided as part of post-rape care by expanding points of access}

While the program successfully increased access to EC in the context of family planning efforts, it was not as effective in making it available to sexual assault survivors. Both clients and providers overwhelmingly identified sexual assault survivors as appropriate clients for $\mathrm{EC}$, but service statistics show that this population did not fully benefit from the program.

Greater access can be created by expanding the provision channels, training and equipping health care workers in a variety of locations to deliver EC as a routine element of post-rape care. A study conducted by ECafrique in Zambia, for example, found that trained police 
officers could effectively provide EC to survivors who presented first to a police station. ${ }^{11}$ This project found that there is public support for such an approach. In Ethiopia, ESOG has developed a model of comprehensive care that delivers EC as part of a one-stop shop for post-rape care in a health facility setting. These models, along with other innovative approaches implemented across Africa, indicate that repositioning of EC can dramatically expand sexual assault survivors' access to the method.

\section{Equip Community-based Reproductive Health Agents (CBRHAs) to deliver EC}

The new cadre of CBRHAs is uniquely positioned to deliver EC services to the broader population including sexual assault survivors. Located close to the community, they can be called upon to provide EC services within the 120-hour window of opportunity, without requiring a costly and time-consuming trip to a health facility. This proximity to the community is especially valuable for sexual assault survivors who may be reluctant to seek formal health care immediately after the assault.

\section{Incorporate EC into national pre- and post- service training curricula for all providers, including those who offer post-rape care}

Training on EC increases the chances that a provider will offer and dispense EC to clients. Nonetheless, very few providers had received training on EC, even in the project sites. It is therefore necessary to train a wide range of providers on EC in order to successfully scale up the services. Such training should not be restricted to only those who deliver family planning services, but should also be extended to those who handle cases of sexual assault.

Pre-service training offers a cost-effective strategy for reaching the widest number of providers. While in-service training is also necessary, integrating EC into the curricula of all medical, nursing and community health schools will ensure that all new graduates are familiar with the method. This will, in turn, allow for uninterrupted services even in locations that experience high provider turnover. It will also relieve the training burden from NGOs, which have almost exclusively provided EC training to date.

\section{Expand training curricula to include the social context of EC provision, and all forms of EC}

An important contribution of this project has been the development of an EC training manual specifically tailored to the needs of Ethiopia. The training program itself has successfully contributed toward increased access to EC in the project sites, most likely by improving provider's confidence in delivering the method.

While the training offered by the project was strong on technical aspects, future training would benefit from an expanded emphasis on the social context of EC provision. In light of the issues that have emerged from the project, key issues for such training should include:

- "Bridging" EC users to other, more effective family planning methods and related reproductive health services. While both clients and providers indicated that family planning advice was often part of EC services, only about half of all EC users actually adopted a new method. Providers inconsistently encouraged EC users to seek HIV/ STI counseling and testing services, and referred sexual assault survivors for

\footnotetext{
${ }^{11}$ Keesbury, Jill (2007) "Emergency Contraception for Survivors of Sexual Assault: New Windows of Opportunity in Zambia." Presentation to the Global Health Conference; Washington, DC.
} 
appropriate care. To ensure that EC serves as a gateway to more comprehensive reproductive healthcare, it is critical to stress "bridging" as a key element of the services.

- Eliminating provider bias against male access to EC. An interesting outcome of the project has been the high level of male involvement in EC. Over half of all women reported consulting their partners before using EC while a surprisingly large number of men obtained it for their partners. However, providers appeared reluctant to offer EC services to this group, potentially limiting their partners' access to the method. Specific training is needed to address gender issues in EC provision (and in family planning in general) to encourage greater male involvement.

To ensure the sustainability of EC services in the face of commodity shortages or the introduction of new products into the country, it is necessary that training does not focus exclusively on Postinor 2. The ESOG curriculum discusses all three methods of ECdedicated EC pills, combined OCPs (Yuzpe method) and IUCDs - with no particular emphasis on a specific brand of dedicated products. Nonetheless, nearly $80 \%$ of those trained by ESOG noted that they were only equipped to provide Postinor 2, with less than half indicating knowledge of other methods. As an element of expanding and mainstreaming EC services in the public sector, efforts should be made to train providers on all methods of EC.

\section{Target young women with high-impact awareness creation activities such as television adverts}

Only $20 \%$ of the men and women interviewed at health facilities had ever heard of EC, and it is likely this proportion is lower among those who do not routinely seek health care. This indicates a clear need for increased awareness-raising activities in the country.

While clinic-level outreach will always remain an important source of health information, ESOG's television adverts proved to be the single most effective media tool. As the government works to increase EC knowledge among the general population, such advertsstrategically aired during popular programming - are most likely to increase the visibility of the method. Young women between the ages of 20-29, who were found to be the most frequent users of EC, should be the target of more intensive media outreach efforts.

Campaigns should also stress the importance of EC as a back-up method both in and outside of marriage, and should include messages on 'bridging'.

\section{Encourage greater EC access through private sector pharmacy provision}

In many countries across Africa, private sector pharmacies dominate EC provision. Clients report that the convenience and anonymity that these pharmacies offer justify the higher price they are charged in comparison to government facilities. While pharmacy provision dramatically increases EC access, it also requires that staff deliver the method responsibly. In other countries, pharmacy access has led to concerns over misuse and repeat use by uninformed clients.

As Ethiopia begins to introduce EC into its private pharmacies, it is critical that pharmacists are well-equipped to deliver this unique method. Key to this approach is ensuring that staff are aware of the issues related to EC provision, are able to encourage clients to use EC only as a back-up method, and are ready to promote 'bridging' where appropriate. Clients often choose pharmacy provision in order to avoid the extensive counseling that accompanies clinic 
access. Approaches to information-sharing in pharmacies therefore need to be innovative and responsive to clients' unique needs.

Both providers and clients agreed that 1 Birr was the optimal price for EC in the private sector. Maintaining such a low price, however, depends on market forces and the availability of competing brands. EC pills from Indian manufacturers are beginning to flood the African market, significantly decreasing consumer prices. With the registration of Postinor 2 in Ethiopia, it is likely that other similar products can be easily registered. This will ensure that the product is more affordable for both government procurement and private sector sales. 